made at random, which gives a good indication of the mean $\mathrm{COHb}$ concentration in smokers. ${ }^{\text {? }}$

A history of an attack of chest pain suggesting myocardial infarction was associated with raised $\mathrm{COHb}$ concentrations; a similar relation was not found for smoking history. The association was unlikely to have been caused by greater frequency of "false" attacks of chest pain in men with raised $\mathrm{COHb}$ concentrations because a similar association was found for ECG signs of myocardial infarction. The association was mainly caused by slight rises in $\mathrm{COHb}$ concentration $\left(0 \cdot 6-2 \cdot 0^{\circ}{ }_{0}\right)$. The finding of this association among ex-smokers was unexpected; occasional smokers who had already had a myocardial infarction may have denied their habit more often than the other men.

Because our subjects were middle-aged and older men from rural areas, we cannot make generalised conclusions. Furthermore, a cross-sectional study such as this has sources of bias: for instance, the men who had diseases associated with smoking may have altered their smoking habits. A prospective population study is needed to clarify the role of carbon monoxide in atherosclerosis.

\section{References}

1 Wald, N, et al, Thorax, 1975, 30, 133.

${ }^{2}$ Karvonen, M J, et al, Acta Medica Scandinavica, 1967, Suppl No 460, $\overrightarrow{\overline{\vec{N}}}$

p 169.
${ }^{3}$ Karvonen, M J, et al, American Heart Association Monograph No 29 , 은

1970, p 52.
${ }^{4}$ Rose, G A, and Blackburn, H, Cardiovascular Survey Methods, Monograph $\frac{\bar{\sigma}}{\overline{\frac{D}{D}}}$ No 56. Geneva, World Health Organisation, 1968.

${ }^{5}$ Blackburn, H, et al, Circulation, 1960, 21, 1160.

${ }^{6}$ Wald, N, et al, British Medical fournal, 1973, 1, 761.

${ }^{7}$ Castleden, C M, and Cole, P V, British Medical fournal, 1974, 4, 736

(Accepted 15 November 1977)

\title{
Influence of induced abortion on gestational duration in subsequent pregnancies
}

\author{
J W VAN DER SLIKKE, P E TREFFERS
}

British Medical fournal, 1978, 1, 270-272

\section{Summary and conclusions}

We studied the effect of previous induced and spontaneous abortion on gestational duration in subsequent pregnancies in 12 obstetric departments in the Netherlands. Only primiparae were studied. Of 504 women who had had a previous induced abortion, $18(3.6 \%)$ delivered before 32 weeks' gestational age. Forty of 1313 women with a history of spontaneous abortion (3.0\%) and 259 of 12678 women with no history of abortion (2.1\%) also delivered before 32 weeks. The differences between the three groups were not significant.

In the Netherlands there are no significant indications that spontaneous midtrimester abortions or premature deliveries are caused by a previous induced abortion.

\section{Introduction}

Should women who have had induced abortions be afraid of additional risk in subsequent, wanted pregnancies ? English ${ }^{1-3}$ and eastern European ${ }^{4-7}$ studies show increased numbers of second-trimester spontaneous abortions and premature deliveries in women becoming pregnant after induced abortions. We aimed to evaluate the risks of such complications in Dutch women.

Since 1967 induced abortions have become more common in the Netherlands. In 1972-3 the estimated number of abortions was $20000-30000,{ }^{8}$ decreasing to $16000-18000$ in 1974 , and 15000 in $1975 . .^{910}$ This last figure gives a rate of approximately 5.5 abortions per 1000 women aged $15-44$ years, or 81 per 1000

\footnotetext{
Department of Obstetrics and Gynaecology, Wilhelmina Gasthuis, University of Amsterdam, The Netherlands

J W VAN DER SLIKKE, MD, senior resident

P E TREFFERS, MD, senior lecturer
}

births. Not more than $5^{\circ}{ }_{0}$ of abortions are induced beyond $12 \stackrel{\oplus}{\circ}$ weeks' gestation, and $95^{\circ}$ of all interventions are performed by minimal dilatation and vacuum aspiration.

\section{Patients and methods}

The analysis was carried out in the department of obstetrics, $\overrightarrow{\vec{B}}$ Wilhelmina Gasthuis, University of Amsterdam. From January 1972 to June 1976 we reviewed 3780 primiparae admitted to this department who delivered at 17 weeks' gestation or more. Of these women, 265 त् $(7.0 \%)$ had had at least one previous induced abortion (group A). The second group consisted of 348 primiparae $(9.2 \%)$ who had had at least one spontaneous abortion and no induced abortions (group B). A third group of 3167 women $(83.8 \%$ ) had had no abortions (group E).

Age-matched controls were selected for each woman in groups A and $\mathrm{B}$ from primiparae delivering immediately afterwards who had no history of abortion (groups $\mathrm{C}$ and $\mathrm{D}$ ). We compared gestational age at delivery between these four groups and between groups $A, B$, $O$ and $\mathrm{E}$. When the date of the last menstrual period was not exactly known, gestational age was estimated from information on prenatal o care, birth weight, and Dubowitz score.

In addition to the material from our own department, we had at our disposal data kindly supplied by GVR (Gemeenschappelijke $\mathrm{N}$ Verloskundige Registratie-that is, Co-operative Obstetric Registra- O tion). In this register, data are collected from 11 obstetric departments $\omega$ in various regions of the Netherlands. ${ }^{11}$ By adding these data to our own, we could study material from 12 departments. From this we 0 selected only primiparae for whom gestational age of pregnancy was known. We excluded women with multiple pregnancies and those who had undergone conisation of the cervix or had uterine scars or congenital malformations of the uterus.

Thus our total series included 14495 primiparae, of whom 12678 had no history of abortion $(87.5 \%), 504$ had had a previous induced abortion $(3.4 \%)$, and 1313 a spontaneous abortion $(9.1 \%)$. We compared gestational age at delivery in these larger groups.

\section{Results}

Table I shows gestational age at delivery in group $\mathrm{A}$ and its matched controls (C) and group B and its matched controls (D). In group A (previous induced abortion) the proportion of deliveries before 32 
weeks $(6.4 \%)$ is higher than that of group C $(1.2 \%)$. The proportion of deliveries between 36 and 37 weeks in group A $(7.9 \%)$ is lower than that of group $\mathrm{C}(13.6 \%)$. This suggests that previous induced abortion may promote early premature or immature delivery $(<32$ weeks) in women - predisposed to deliver late premature (36-37 weeks). Nevertheless, the statistical significance is poor $\left(P=0.05, \chi^{2}\right.$ test $)$.

Women with a history of spontaneous abortion (group B) had a similar proportion of deliveries before 32 weeks $(4.6 \%)$ to group A, but the proportion of early premature deliveries among their controls (group D) was also similar (3.8\%). There was no significant difference between groups $\mathrm{A}, \mathrm{B}$, and $\mathrm{D}\left(\mathbf{P}, 0 \cdot 2, \chi^{2}\right.$ test $)$, and no difference between $\mathrm{B}, \mathrm{C}$, and $\mathrm{D}$.

Table II compares group A (previous induced abortion) with

TABLE I-Gestational age at delivery in primiparae with a history of induced or spontaneous abortion and their age-matched controls. Figures are numbers (\%) of primiparae

\begin{tabular}{|c|c|c|c|c|}
\hline Group: & A & $\mathrm{C}$ & B & $\mathrm{D}$ \\
\hline $\begin{array}{l}\text { Gestational age } \\
\text { of pregnancy } \\
\text { (weeks) }\end{array}$ & $\begin{array}{l}\text { Previous } \\
\text { induced } \\
\text { ábortion }\end{array}$ & No abortion & $\begin{array}{l}\text { Previous } \\
\text { spontaneous } \\
\text { abortion }\end{array}$ & No abortion \\
\hline $\begin{array}{c}17-27 \\
28-31 \\
32-35 \\
36-37 \\
38-41 \\
\geq 42\end{array}$ & $\begin{array}{r}7(2 \cdot 6) \\
10(3 \cdot 8) \\
15(5 \cdot 7) \\
21(7 \cdot 9) \\
187(70 \cdot 6) \\
25(9 \cdot 4)\end{array}$ & $\begin{aligned} & 1(0 \cdot 4)(0 \cdot 8) \\
& 2(0 \cdot 8) \\
& 16(6 \cdot 0) \\
& 36(13 \cdot 6) \\
& 183(69 \cdot 1) \\
& 27(10 \cdot 2)\end{aligned}$ & $\begin{aligned} 10 & (2 \cdot 9) \\
6 & (1 \cdot 7) \\
18 & (5 \cdot 2) \\
36 & (10.3) \\
246 & (70 \cdot 7) \\
32 & (9 \cdot 2)\end{aligned}$ & $\begin{array}{r}3(0 \cdot 9) \\
10(2 \cdot 9) \\
17(4 \cdot 9) \\
34(9 \cdot 8) \\
249(71 \cdot 6) \\
35(10 \cdot 1)\end{array}$ \\
\hline Total & $265(100)$ & $265(100)$ & $348(100)$ & $348(100)$ \\
\hline
\end{tabular}

TABLE II-Gestational age at delivery in primiparae with a history of induced or spontaneous abortion compared with that in all primiparae with no history of induced abortion. Figures are numbers (\%) of primiparae

\begin{tabular}{c|c|c|c}
\hline Group: & $\mathrm{A}$ & $\mathrm{E}$ & $\mathrm{B}$ \\
\cline { 1 - 3 } $\begin{array}{c}\text { Gestational age } \\
\text { of pregnancy } \\
\text { (weeks) }\end{array}$ & $\begin{array}{c}\text { Previous } \\
\text { induced } \\
\text { abortion }\end{array}$ & No abortion & $\begin{array}{c}\text { Previous } \\
\text { spontaneous } \\
\text { abortion }\end{array}$ \\
\hline $17-27$ & $7(2 \cdot 6)$ & $40(1 \cdot 3)$ & $10(2 \cdot 9)$ \\
$28-31$ & $10(3 \cdot 8)$ & $60(1 \cdot 9)$ & $6(1 \cdot 7)$ \\
$32-35$ & $15(5 \cdot 7)$ & $165(5 \cdot 2)$ & $18(5 \cdot 2)$ \\
$36-37$ & $21(7 \cdot 9)$ & $290(9 \cdot 1)$ & $36(10 \cdot 3)$ \\
$38-41$ & $187(70 \cdot 6)$ & $2295(72 \cdot 5)$ & $246(70 \cdot 7)$ \\
$25(9 \cdot 4)$ & $317(10 \cdot 0)$ & $32(9 \cdot 2)$ \\
\hline Total & $265(100)$ & $3167(100)$ & $348(100)$ \\
\hline
\end{tabular}

TABLE III-Gestational age at delivery in primiparae with a history of induced or spontaneous abortion compared with that in primiparae with no history of abortion in 12 obstetric departments. Figures are numbers (\%) of primiparae

\begin{tabular}{c|c|c|c}
\hline $\begin{array}{c}\text { Gestational age } \\
\text { of pregnancy } \\
\text { (weeks) }\end{array}$ & $\begin{array}{c}\text { Previous } \\
\text { induced } \\
\text { abortion }\end{array}$ & No abortion & $\begin{array}{c}\text { Previous } \\
\text { spontaneous } \\
\text { abortion }\end{array}$ \\
\hline $17-27$ & $9(1 \cdot 8)$ & $99(0 \cdot 8)$ & $24(1 \cdot 8)$ \\
$28-31$ & $9(1 \cdot 8)$ & $160(1 \cdot 3)$ & $16(1 \cdot 2)$ \\
$32-35$ & $21(4 \cdot 2)$ & $477(3 \cdot 8)$ & $50(3 \cdot 8)$ \\
$36-37$ & $40(7 \cdot 9)$ & $953(7 \cdot 5)$ & $96(7 \cdot 3)$ \\
$38-41$ & $358(71 \cdot 0)$ & $9038(71 \cdot 2)$ & $958(73 \cdot 0)$ \\
$\geqslant 42$ & $67(13 \cdot 3)$ & $1951(15 \cdot 4)$ & $169(12 \cdot 9)$ \\
\hline Total & $504(100)$ & $12678(100)$ & $1313(100)$ \\
\hline
\end{tabular}

TABLE IV-Gestational duration of pregnancy in 3780 primiparae (with and without history of abortion) according to age. Figures are percentages of primiparae

\begin{tabular}{|c|c|c|c|c|c|c|}
\hline \multirow{2}{*}{$\begin{array}{l}\text { Duration of } \\
\text { pregnancy } \\
\text { (weeks) }\end{array}$} & \multicolumn{5}{|c|}{ Age (years) } & \multirow{2}{*}{$\begin{array}{c}\text { Total } \\
(n=3780)\end{array}$} \\
\hline & $\begin{array}{c}\leqslant 19 \\
(n=735)\end{array}$ & $\begin{array}{c}20-24 \\
(n=1717)\end{array}$ & $\begin{array}{c}25-29 \\
(\mathrm{n}=1017)\end{array}$ & $\begin{array}{c}30-34 \\
(n=253)\end{array}$ & $\begin{array}{l}\geqslant 35 \\
(n=58)\end{array}$ & \\
\hline $\begin{array}{r}17-27 \\
28-31 \\
32-35 \\
36-37 \\
38-41 \\
\geqslant 42\end{array}$ & $\begin{array}{r}2.0 \\
2.0 \\
5.0 \\
9 \cdot 3 \\
71.3 \\
10.3\end{array}$ & $\begin{array}{r}1 \cdot 1 \\
1.9 \\
5 \cdot 4 \\
9 \cdot 3 \\
72 \cdot 7 \\
10 \cdot 2\end{array}$ & $\begin{array}{r}1 \cdot 5 \\
2 \cdot 2 \\
4.9 \\
9 \cdot 1 \\
73 \cdot 1 \\
9.2\end{array}$ & $\begin{array}{r}2 \cdot 0 \\
2 \cdot 4 \\
6 \cdot 7 \\
8 \cdot 3 \\
71 \cdot 2 \\
9 \cdot 5\end{array}$ & $\begin{array}{r}5 \cdot 2 \\
1 \cdot 7 \\
3.5 \\
10 \cdot 3 \\
70 \cdot 7 \\
8 \cdot 6\end{array}$ & $\begin{array}{r}1.5 \\
2.0 \\
5.2 \\
9 \cdot 2 \\
72 \cdot 2 \\
9.9\end{array}$ \\
\hline
\end{tabular}

groups $\mathrm{B}$ and $\mathrm{E}$ (no history of induced abortion). There seems to be a twofold increase of deliveries before 32 weeks in group A compared with group $\mathrm{E}(6.4 \% v 3.2 \%)$, but this difference is not significant (P>0.2, $\chi^{2}$ test).

Table III shows the total material from the 12 departments. The differences in gestational age at delivery between the three groups of women are not significant. Premature deliveries were evenly distributed among the different age groups of patients in our department (table IV).

\section{Discussion}

Much has been published about the direct complications of induced abortion, less about the latent morbidity becoming apparent in subsequent pregnancies. We are still uncertain whether gestational duration is influenced by a previous induced abortion, and to what extent.

Many other factors influence duration of pregnancy-for example, multiple pregnancy, conisation of the cervix, hydramnios-and possibly age, parity and social class, height of mother and father, sex of the fetus, and smoking during pregnancy. ${ }^{12}$ In the data from our own department (tables I, II) we standardised parity (only primiparae were considered), and we selected agematched controls. In the material from 12 departments (table III) we excluded factors known to cause premature delivery (multiple pregnancy, prior conisation of cervix, congenital malformations of uterus). The proportion of immature and premature deliveries in the total series was therefore lower than that of our own department. Moreover, the Wilhelmina Gasthuis is a centre where premature deliveries are concentrated. ${ }^{12}$

The results from our own department suggest only a slight tendency to increased risk of spontaneous midtrimester abortion or early premature delivery in women who have undergone induced abortion in a previous pregnancy. But this difference is not significant. In the larger material from 12 departments this trend is negligible. We cannot exclude the possibility that a previous induced abortion (with dilatation of the cervix) is more likely to be harmful when combined with other factors predisposing to prematurity. Some of these factors were excluded in the larger study. The influence of a previous induced abortion on duration of subsequent pregnancy was slight in our study, and certainly not as great as the effect reported by Wright, ${ }^{1}$ who found a tenfold increase in midtrimester abortions. Of course our results are applicable only to the Netherlands, where most abortions are performed early in pregnancy, and by minimal dilatation. They do not apply to the possible late complications of abortions performed vaginally after 12 weeks' gestation, and by excessive dilatation.

Daling ${ }^{13}$ asserts that if patients and controls are matched for social class, parity, age, and prior incidence of fetal death, all relations between previous abortions and complications in the outcome of subsequent pregnancies disappear. In her study, however, details of gestational age and birth weight were apparently unavailable in many cases. We studied only primiparae, and therefore excluded the influence of parity and prior fetal death. Premature deliveries were evenly distributed among the different age groups in our department (table IV). We did not match patients for social class. Such standardisation, however, would probably have made the possible harmful effects of previous abortion even less apparent.

Women delivering prematurely may be questioned more closely about their obstetric history and may be more likely to admit to a previous induced abortion than women with uncomplicated pregnancies. This would produce a seemingly stronger correlation between previous induced abortion and premature delivery. If this were so, the differences in outcome of pregnancy between women with and without a history of abortion would be even smaller than they seem to be now.

We conclude that induced abortion may lead to immature or premature delivery in a subsequent pregnancy in individual 
cases, but that the general risk of such complications to women in the Netherlands is slight when abortion has been performed by early vacuum aspiration.

We thank the participants in GVR for their kind co-operation, W Breur for the statistical evaluation, and B L Huidekoper for gathering obstetric data.

\section{References}

1 Wright, C S W, Campbell, S, and Beazley, J, Lancet, 1972, 1, 1278.

2 Wynn, M, and Wynn, A, Some Consequences of Induced Abortion to Children Born Subsequently. London, Foundation for Education and Research in Child-bearing, 1972.

${ }^{3}$ Richardson, J A, and Dixon, G, British Medical fournal, 1976, 1, 1303.
${ }^{4}$ Kotásek, A, in 4th European Congress of Perinatal Medicine 1974, ed Z K Stembera, et al, p 183. Stuttgart, Thieme, 1975.

${ }^{5}$ Lembrych, V S, Zentralblatt für Gynäkologie, 1972, 94, 164.

${ }^{6}$ Pantelakis, S N, Papadimitriou, G C, and Doxiadis, S A, American fournal of Obstetrics and Gynecology, 1973, 116, 799.

${ }^{7}$ Papaevangelou, G, et al, fournal of Obstetrics and Gynaecology of the British Commonwealth, 1973, 80, 418.

${ }^{8}$ Treffers, P E, European fournal of Obstetrics, Gynecology, and Reproductive Biology, 1973, 3, 173.

${ }^{9}$ Schnabel, P, Abortus in Nederland. The Hague, Stimezo Nederland, 1976.

${ }^{10}$ Schnabel, P, Medisch Contact, 1976, 31, 581.

${ }^{11}$ Hemel, O J S, van, An Obstetric Data Base, MD thesis. Amsterdam, $\stackrel{9}{\square}$ Vrije Universiteit, 1977.

${ }^{12}$ Kloosterman, G J, in 4th European Congress of Perinatal Medicine 1974, $\frac{C}{\partial}$ ed Z K Stembera et al, p 194. Stuttgart, Thieme, 1975.

${ }_{13}$ Daling, J R, and Emanuel, I, Lancet, 1975, 2, 170.

\title{
Oral anticoagulants controlled by the British comparative thromboplastin versus low-dose heparin in prophylaxis of deep vein thrombosis
}

\author{
D A TABERNER, L POLLER, R W BURSLEM, J B JONES
}

British Medical fournal, 1978, 1, 272-274

\section{Summary and conclusions}

The British comparative thromboplastin (BCT) was us d to monitor the effectiveness of oral anticoagulants in preventing deep vein thrombosis (DVT) in patients undergoing major gynaecological surgery. All patients were screened for DVT with the use of the ${ }^{125}$ I-fibrinogen scan.

One hundred and forty-five patients aged 40 years or more were randomised into three groups. Group 1 received oral anticoagulant (nicoumalone) treatment, stabilised over five days before surgery and continuing into the second postoperative week. The other patients served as two contrast groups and were managed on a double-blind basis. Group 2 received a subcutaneous low-dose regimen of heparin calcium. Group 3 received subcutaneous saline. Eleven of 48 patients in the saline group, three of 49 patients in the heparin group, and three of 48 patients in the oral anticoagulant group developed DVT as judged by ${ }^{125} I$-fibrinogen scanning. The incidences in groups 1 and 2 were significantly lower than in the saline group. The falls in haemoglobin concentration and incidence of haemorrhage were similar in all three groups.

The study showed that oral anticoagulant prophylaxis stabilised preoperatively and low-dose heparin were equally effective in preventing deep vein thrombosis in a

\footnotetext{
National Reference Laboratory for Anticoagulant Control Reagents, Withington Hospital, Manchester M20 8LR

D A TABERNER, BM, MRCP, senior registrar in haematology L POLLER, MD, FRCPATH, consultant haematologist

Withington Hospital, University Hospital of South Manchester, Manchester M20 8LR

R W BURSLEM, MD, FRCOG, consultant obstetrician and gynaecologist J B JONES, FRCS, FRCOG, consultant obstetrician and gynaecologist
}

moderate-risk group. Immediate preoperative pro- $\vec{\varphi}$ thrombin ratios of $2 \cdot 0-2 \cdot 5$ and postoperative ratios of $\infty$ 2.0-4.0 with the BCT gave adequate protection without increased haemorrhagic risk.

\section{Introduction}

The value of oral anticoagulants in preventing venous thrombosis $\overrightarrow{\vec{O}}$ is generally accepted. With the advent of scanning techniques 3 using ${ }^{125} \mathrm{I}$-labelled fibrinogen their effectiveness in preventing deep vein thrombosis in surgical patients may be objectively assessed without having to rely on clinical signs. Morris and Mitchell ${ }^{1}$ used the labelled fibrinogen scan to show that oral anticoagulants controlled by the Thrombotest method protect elderly patients with hip trauma from venous thrombosis. Nevertheless, studies on patients undergoing general ${ }^{2}$ or gynaecological $^{3}$ surgery have produced less favourable results with oral anticoagulants than with a low-dose heparin regimen. 0 In both these studies oral anticoagulants were started only postoperatively, and thrombosis often occurred before the OD anticoagulants reached therapeutic concentrations.

The recommended method for laboratory control of anticoagulants in Britain is based on the British comparative $N$ thromboplastin (BCT), which is also widely used as a reference $N$ reagent abroad. The recommended therapeutic range based on clinical experience is a prothrombin ratio from 2.0 to 4.0 with 0 this reagent. We therefore set out to evaluate the effectiveness $\frac{\bar{D}}{\mathbb{D}}$ of this therapeutic range in preventing venous thrombosis by $\stackrel{0}{?}$ using ${ }^{125} \mathrm{I}$-fibrinogen scanning. We studied patients aged over ${ }^{0}$ 40 years who were undergoing major gynaecological surgery. One group received oral anticoagulants and two parallel groups were given either subcutaneous low-dose heparin or saline on a $\stackrel{\mathbb{Q}}{\Omega}$ double-blind basis. Low-dose heparin has been shown to be an $\bar{\sigma}$ effective prophylaxis in such patients. ${ }^{4}$

\section{Patients and methods}

One hundred and forty-five patients aged 40 years or more who were having major abdominal or vaginal surgery were randomly allocated 